\section{Type IV Hiatal Hernia Containing the Gastric Pouch and Proximal Roux Limb: A Rare Cause of Bowel Obstruction Following Roux-en-Y Bypass Surgery}

Michael E. Nance ${ }^{1}$, Emanuel Shapera ${ }^{2}$, Andrew A. Wheeler ${ }^{3}$

1. Internal Medicine, University of Missouri-Columbia, Columbia, USA 2. General Surgery, University of MissouriColumbia, Columbia, USA 3. Surgery, University of Missouri-Columbia, Columbia, USA

Corresponding author: Andrew A. Wheeler, wheeleraa@health.missouri.edu
Received 07/31/2020

Review began $08 / 03 / 2020$ Review ended 08/21/2020 Published 08/30/2020

(c) Copyright 2020

Nance et al. This is an open access article distributed under the terms of the Creative Commons Attribution License CC-BY 4.0., which permits unrestricted use, distribution, and reproduction in any medium, provided the original author and source are credited.

\begin{abstract}
Roux-en-Y gastric bypass (RYGB) is considered the gold standard for weight loss surgery and is an effective, safe treatment for morbid obesity and associated metabolic derangements. Complications such as small bowel obstruction are rare with a reported incidence of $5 \%$. Obstruction caused by hiatal herniation of the gastric pouch and alimentary limb occurs even less frequently. Prompt recognition and treatment are imperative as delayed intervention may result in significant morbidity. At the time of this manuscript there have only been four reported cases in the literature highlighting a paucity of clinical guidance for the recognition and management of this complication. Here we present a case of acute small bowel obstruction secondary to hiatal herniation of the gastric pouch and proximal Roux limb. Furthermore, we review the literature and discuss the key aspects for the management of this complication.
\end{abstract}

Categories: Endocrinology/Diabetes/Metabolism, Gastroenterology, General Surgery

Keywords: roux-en-y gastric bypass, hiatal hernia, small bowel obstruction, weight loss surgery, bariatric surgery, gastric bypass complications, laparoscopic surgery

\section{Introduction}

Roux-en-Y gastric bypass (RYGB) is effective in the treatment of morbid obesity and its associated metabolic derangements $[1,2]$. However, complications such as small bowel obstruction can rarely occur and may be observed in approximately $5 \%$ of cases [3]. Obstruction via hiatal herniation of the gastric pouch and alimentary limb occurs even less frequently, with only four cases reported in the literature [4-7]. We present a case of acute small bowel obstruction 12 years after RYGB caused by herniation of the gastric pouch and proximal Roux limb into a hiatal hernia as well as our management of this condition.

\section{Case Presentation}

A 68-year-old female presented with a one-year history of progressive nausea, emesis, and sharp epigastric abdominal pain leading to eventual acute intolerance of oral intake for four days. She previously underwent a retro-colic Roux-en-Y gastric bypass (RYGB) surgery 12 years prior for treatment of her morbid obesity. Eight weeks prior to presentation, she underwent magnetic resonance cholangiopancreatography for evaluation of her chronic symptoms. Imaging revealed a large hiatal hernia containing the gastric fundus and the absence of any additional acute processes (Figure 1). On presentation to the emergency department, a computed tomography (CT) scan of abdomen without contrast was obtained due to her worsening epigastric abdominal pain and intolerance to liquids and solids, which showed the gastric pouch and Roux limb herniated into the thorax with obstruction of Roux limb and a clear transition point at the esophageal hiatus (Figure $2 A$ and B). Given these concerning findings, the patient was taken to the operating room for emergent laparoscopic hiatal hernia repair. 


\section{Cureus}

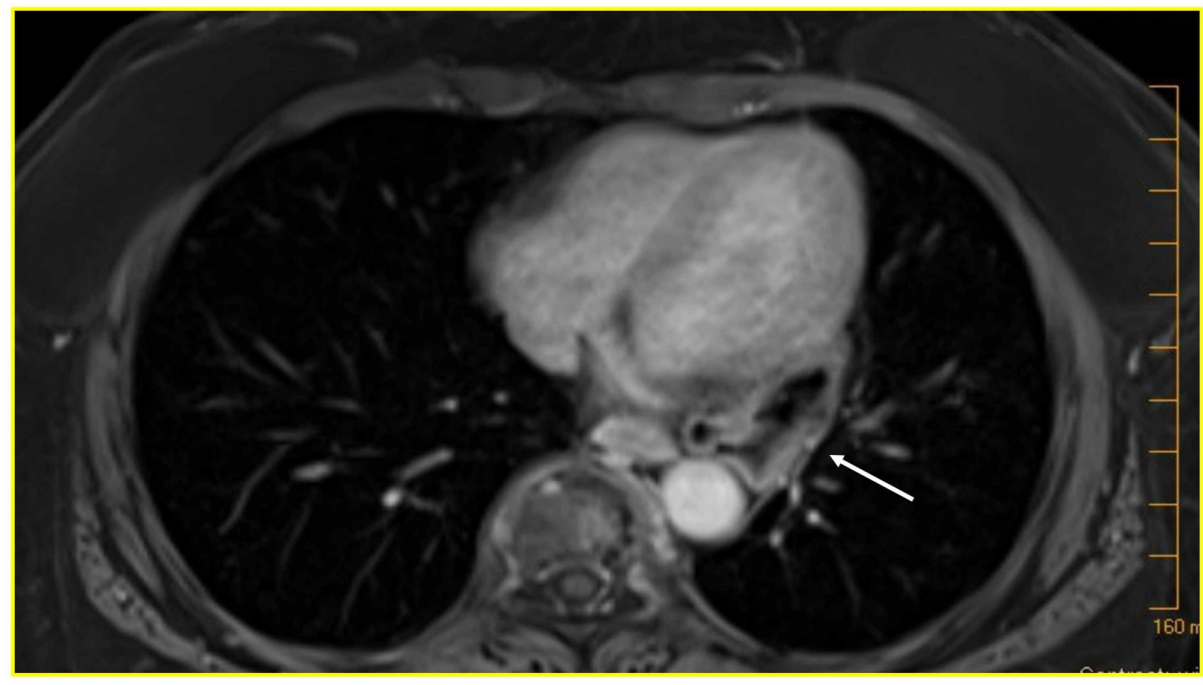

\section{FIGURE 1: Gastric pouch herniation 12 years post Roux-en-Y bypass}

surgery

T1-weighted axial magnetic resonance image abdomen and pelvis with gadolinium contrast demonstrating the herniated gastric pouch (white arrow, herniated gastric pouch).
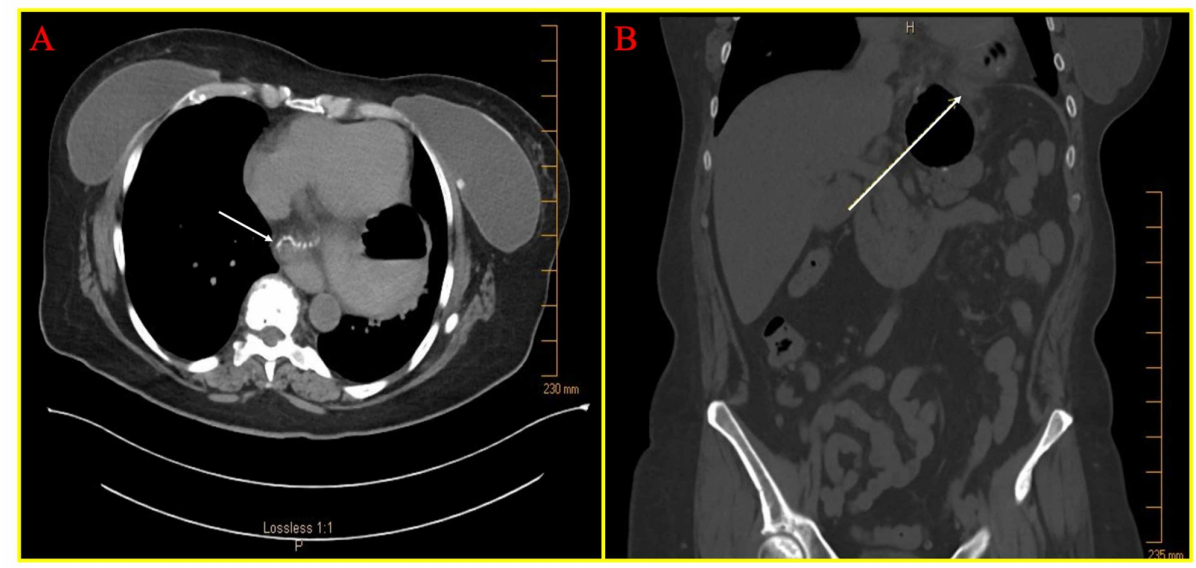

\section{FIGURE 2: Pre-operative imaging demonstrating gastric pouch and} proximal Roux-limb herniation

Computed tomography abdomen and pelvis without contrast showing (A) axial and (B) coronal sections demonstrating the herniated Roux limb and gastric pouch prior to surgery (white arrows, herniated Roux limb).

An optical trocar was utilized to gain entry into the abdominal cavity. Exploration of the esophageal hiatus was performed. A type IV hiatal hernia involving the entire gastric pouch and proximal Roux limb was identified. The bowel was distended and edematous but viable. The pars flaccida was opened with a laparoscopic bipolar vessel sealer, which demonstrated the left crus being densely adherent to the Roux limb. After careful dissection, the hernia sac and contents including gastric pouch and proximal Roux limb were reduced out of the hiatus. The gastric pouch and Roux limb were closely inspected, both of which appeared viable. The anterior and posterior hernia sacs were separated from the bilateral crus and mediastinal structures until the contents were reduced and adequate esophageal length was obtained. A posterior cruroplasty was performed with 2-0 Ethibond suture. Intraoperative upper endoscopy confirmed smooth passage along the length of the esophagus, a normal appearing gastric pouch, patent gastrojejunostomy free from stricture and ulceration with a dilated yet viable Roux limb. Upper gastrointestinal study on post-operative day one demonstrated no leak or obstruction of contrast passage. She was discharged on post-operative day three with resolution of her symptoms except mild nausea. 
At one-, nine-, and 27-month post-operative follow-up visits, the patient reported complete resolution of symptoms, improved tolerance of liquids and solids, and regular bowel function.

\section{Discussion}

According to the American Society for Metabolic and Bariatric Surgery, 252,000 metabolic operations were performed in 2018 for obesity and its associated metabolic derangement, with RYGB accounting for $17 \%$ of the total operations [8]. Hiatal hernias are common in patients undergoing weight loss surgery, occurring in up to $40 \%$ of patients. Often times, morbidly obese patients have hiatal hernias identified when undergoing weight loss surgery [9]. Utilizing the Metabolic and Bariatric Surgery Association Quality Improvement Project patient use files, paraesophageal hernia repairs have been reported in $16 \%$ of patients undergoing weight loss surgery [10]. This represents a significant percentage of weight loss surgery patients who have paraesophageal hernias repaired at the time of their operation, but based on reported rates of hiatal hernias in patients having weight loss surgery this indicates that a significant number of patients do not have their hiatal hernia repaired during their index weight loss surgery. Particularly, small hiatal hernias may not be repaired during the index operation, especially in patients having a gastric bypass compared to sleeve gastrectomy and, thus, may set the patient up for subsequent complications at a remote point from their operation [11].

Hiatal hernia occurrence after RYGB can occur quite frequently after gastric bypass [12]. The relatively small size of the gastric pouch, dissection injury to sling fibers, and tissue strength changes related to rapid weight loss may all predispose patients to post-operative hiatal hernia occurrence after gastric bypass. Several small case series have been published describing the repair of hiatal hernias after gastric bypass with the largest series reporting seven patients with hiatal hernia repair after gastric bypass [9]. In the event of acutely worsening abdominal pain, nausea, and vomiting, clinicians should have a high suspicion for acute small bowel obstruction in RYGB patients and be quick to proceed with evaluation and surgical intervention. Patients with hiatal hernia after gastric bypass may present similar to this patient with chronic symptoms and may include dysphagia, post-prandial epigastric pain, or nausea and/or vomiting [9]. Diagnostic imaging and upper endoscopy may reveal the diagnosis of gastric bypass pouch herniation into the esophageal hiatus, but rarely patients may present acutely with a bowel obstruction from Roux limb herniation.

A review of the literature identified four reported cases making our patient only the fifth reported case of bowel obstruction from a hiatal hernia after gastric bypass (Table 1) [4-7]. Of the four previous cases, all presented with abdominal pain, nausea, and emesis. Additional reported symptoms included shortness of breath and constipation. Time to presentation ranged from four to 48 months (mean 16.75 months) after the index RYGB. Only one case included herniation of the omentum and transverse colon in addition to the gastric pouch and Roux limb. Two of four cases (50\%) had a history of hiatal hernia repair at the time of RYGB, thus representing a recurrent hiatal hernia. All cases were successfully managed with anterior $(1 / 4$ cases) or posterior (3/4 cases) cruroplasty with or without mesh and did not require bowel resection. Followup ranged from four weeks to 12 months with no reported recurrence of symptoms. Due to the limited number of cases, it was not possible to evaluate any effect of hiatal hernia repair at the time of RYGB, gastric pouch size, amount of weight loss, or retro-colic versus ante-colic Roux limb position. 


\begin{tabular}{|c|c|c|c|c|c|c|c|c|c|c|c|}
\hline $\begin{array}{l}\text { Case } \\
\#\end{array}$ & Operative diagnoses & Sex & Age & Presentation & $\begin{array}{l}\text { Weight } \\
\text { loss }\end{array}$ & $\begin{array}{l}\text { Time } \\
\text { post- } \\
\text { RYGB }\end{array}$ & $\mathrm{HH}$ repair & $\begin{array}{l}\text { Bowel } \\
\text { viable }\end{array}$ & $\begin{array}{l}\text { Symptom } \\
\text { recurrence }\end{array}$ & Comments & Reference \\
\hline 1 & $\begin{array}{l}\text { Hiatal hernia containing } \\
\text { gastric pouch, Roux limb, } \\
\text { omentum, and transverse } \\
\text { colon }\end{array}$ & $\mathrm{F}$ & 43 & $\begin{array}{l}\text { Constant upper abdominal } \\
\text { pain with vomiting, anorexia, } \\
\text { shortness of breath, and } \\
\text { constipation }\end{array}$ & $\begin{array}{l}>82 \% \\
\text { excess } \\
\text { weight }\end{array}$ & $\begin{array}{l}9 \\
\text { months }\end{array}$ & $\begin{array}{l}\text { Laparoscopic; } \\
\text { cruroplasty } \\
\text { with mesh }\end{array}$ & Yes & $\begin{array}{l}\text { None; 4- } \\
\text { week } \\
\text { follow-up }\end{array}$ & $\begin{array}{l}\text { No hernia } \\
\text { sac } \\
\text { indicating } \\
\text { acute } \\
\text { herniation } \\
\text { without } \\
\text { trauma }\end{array}$ & $\begin{array}{l}\text { Borg et al. } \\
2011 \text { [5] }\end{array}$ \\
\hline 2 & $\begin{array}{l}\text { Hiatal hernia containing } \\
\text { gastric pouch and entire } \\
\text { Roux limb }\end{array}$ & $\mathrm{F}$ & 47 & $\begin{array}{l}\text { Sudden onset epigastric pain } \\
\text { with nausea and vomiting }\end{array}$ & $\begin{array}{l}71 \\
\text { pounds }\end{array}$ & $\begin{array}{l}6 \\
\text { months }\end{array}$ & $\begin{array}{l}\text { Laparoscopic; } \\
\text { posterior } \\
\text { cruroplasty } \\
\text { with mesh }\end{array}$ & Yes & $\begin{array}{l}\text { None; 6- } \\
\text { month } \\
\text { follow-up }\end{array}$ & $\begin{array}{l}\text { HH repair at } \\
\text { time of } \\
\text { RYGB }\end{array}$ & $\begin{array}{l}\text { Caceres et } \\
\text { al. } 2010 \\
{[6]}\end{array}$ \\
\hline 3 & $\begin{array}{l}\text { Hiatal hernia containing } \\
\text { gastric pouch and proximal } \\
\text { Roux limb }\end{array}$ & $\mathrm{F}$ & 28 & $\begin{array}{l}\text { Severe, colicky epigastric pain } \\
\text { with nausea and vomiting }\end{array}$ & $\begin{array}{l}\text { Not } \\
\text { reported }\end{array}$ & $\begin{array}{l}4 \\
\text { months }\end{array}$ & $\begin{array}{l}\text { Open; anterior } \\
\text { cruroplasty } \\
\text { without mesh }\end{array}$ & Yes & $\begin{array}{l}\text { None; 12- } \\
\text { month } \\
\text { follow-up }\end{array}$ & $\begin{array}{l}\text { HH repair at } \\
\text { time of } \\
\text { RYGB }\end{array}$ & $\begin{array}{l}\text { Cardaci et } \\
\text { al. } 2017 \\
{[7]}\end{array}$ \\
\hline 4 & $\begin{array}{l}\text { Hiatal hernia containing } \\
\text { gastric pouch and proximal } \\
\text { Roux limb }\end{array}$ & $\mathrm{F}$ & 68 & $\begin{array}{l}\text { Sudden onset mid-epigastric } \\
\text { pain }\end{array}$ & $\begin{array}{l}150 \\
\text { pounds }\end{array}$ & $\begin{array}{l}48 \\
\text { months }\end{array}$ & $\begin{array}{l}\text { Laparoscopic; } \\
\text { cruroplasty } \\
\text { without mesh }\end{array}$ & Yes & $\begin{array}{l}\text { Not } \\
\text { reported }\end{array}$ & None & $\begin{array}{l}\text { Pandya et } \\
\text { al. } 2011 \\
\text { [4] }\end{array}$ \\
\hline
\end{tabular}

TABLE 1: Cases of Roux limb hiatal hernia causing bowel obstruction

In the presented case, a diagnosis of obstruction was suspected based on the patient's history of protracted, intermittent abdominal pain, nausea, vomiting, and constipation. Although a large hiatal hernia containing gastric pouch was identified on MRI, the Roux limb was not within the hernia, suggesting spontaneous herniation of the alimentary limb leading to the patient's acute-on-chronic symptoms. This would explain the patient's prior intermittent symptoms, which worsened upon Roux limb incarceration a few days prior to presentation. This phenomenon of acute-on-chronic symptoms has also been observed with internal hernias leading to acute presentation requiring operative intervention $[13,14]$.

A laparoscopic approach to this patient was undertaken for the demonstrated benefits of laparoscopic versus open paraesophageal hernia repair in the non-bariatric surgery patient [15]. Key tenets of the repair of hiatal hernias after gastric bypass include those pertinent to non-gastric bypass patients with what we feel are some additional components when repairing hiatal hernias after gastric bypass [16]. First, it is important to carefully dissect the gastric pouch along its lateral margin where it is often densely adherent to the remnant stomach due to the adjacent staple lines. At this point, separation of the gastric pouch and remnant stomach should be undertaken if any cephalad retraction of the pouch is present once the rest of the hernia reduced, if adequate intra-abdominal esophageal length cannot be obtained, or to aid in adequate exposure of the left diaphragmatic crus. Next, care should be undertaken along the left crura and left side of mediastinum as the gastric pouch staple line can be densely adherent to adjacent structures. Bioabsorbable mesh can be considered depending on the status of the cruroplasty. Lastly, internal hernias should be inspected for during the operation as well as anytime a patient with a gastric bypass is returned to the operating room for an intra-abdominal procedure.

Small bowel obstruction after RYGB often requires urgent surgical intervention as compared to small bowel obstruction in non-bariatric patients where a period of non-operative therapy can be trialed. Therefore, timely diagnosis is critical to provide timely operative intervention. In the absence of more common causes of bowel obstruction after RYGB, such as internal hernia, abdominal adhesions, or even small bowel intussusception, the treating physician must be aware of the possibility of hiatal herniation of the alimentary limb as a possible cause to avoid a delay in diagnosis and treatment.

\section{Conclusions}

Bowel obstruction after RYGB is not uncommon. Obstruction from a hiatal hernia containing the gastric pouch and Roux limb is infrequent but carries the potential for significant morbidity. Treating physicians must remain cognizant of this possibility as prompt diagnosis and treatment are crucial. Laparoscopic repair is safe, effective, and can permit fast recovery. This case report demonstrates an appropriate course of management for patients to consider when treating this condition. 


\section{Additional Information \\ Disclosures}

Human subjects: Consent was obtained by all participants in this study. University of Missouri Columbia issued approval 2019782. Conflicts of interest: In compliance with the ICMJE uniform disclosure form, all authors declare the following: Payment/services info: All authors have declared that no financial support was received from any organization for the submitted work. Financial relationships: All authors have declared that they have no financial relationships at present or within the previous three years with any organizations that might have an interest in the submitted work. Other relationships: All authors have declared that there are no other relationships or activities that could appear to have influenced the submitted work.

\section{References}

1. MacDonald, Jr. KG: Overview of the epidemiology of obesity and the early history of procedures to remedy morbid obesity. Arch Surg. 2003, 138:357-360. 10.1001/archsurg.138.4.357

2. Suter M, Calmes JM, Paroz A, Romy S, Giusti V: Results of Roux-en-Y gastric bypass in morbidly obese vs superobese patients: similar body weight loss, correction of comorbidities, and improvement of quality of life. Arch Surg. 2009, 144:312-318. 10.1001/archsurg.2009.19

3. Gunabushanam G, Shankar S, Czerniach DR, Kelly JJ, Perugini RA: Small-bowel obstruction after laparoscopic Roux-en-Y gastric bypass surgery. J Comput Assist Tomogr. 2009, 33:369-375. 10.1097/RCT.0b013e31818803ac

4. Hiatal hernias causing post operative bowel obstruction following Roux en Y gastric bypass . (2011). Accessed: July 29, 2020: https://c8g3e5x4.rocketcdn.me/wp-content/uploads/posters/2011/33643.jpg.

5. Borg CM, Katz-Summercorn A, Adamo M: Acute diaphragmatic herniation as cause of small bowel obstruction after gastric bypass. Surg Obes Relat Dis. 2011, 7:6-8. 10.1016/j.soard.2010.07.010

6. Caceres M, Eid GM, McCloskey CA: Recurrent paraesophageal hernia presenting as obstruction of Roux limb after Roux-en-Y gastric bypass. Surg Obes Relat Dis. 2010, 6:197-199. 10.1016/j.soard.2009.10.008

7. Cardaci MB, Keuleneer R, Massaarani F: Hiatal hernia containing the alimentary limb and the gastric pouch: a rare cause of small bowel obstruction after Roux-en-Y gastric bypass. Surg Obes Relat Dis. 2017, 13:19291931. 10.1016/j.soard.2017.08.014

8. Estimate of Bariatric Surgery Numbers, 2011-2018, American Society for Metabolic and Bariatric Surgery . (2018). Accessed: July 29, 2020: https://asmbs.org/resources/estimate-of-bariatric-surgery-numbers.

9. Clapp B, Vo LU, Lodeiro C, Harper B, Montelongo S, Lee I, Tyroch A: Late-term hiatal hernia after gastric bypass: an emerging problem. Surg Obes Relat Dis. 2020, 16:471-475. 10.1016/j.soard.2020.01.018

10. Hefler J, Dang J, Mocanu V, Switzer N, Birch DW, Karmali S: Concurrent bariatric surgery and paraesophageal hernia repair: an analysis of the Metabolic and Bariatric Surgery Association Quality Improvement Program (MBSAQIP) database. Surg Obes Relat Dis. 2019, 15:1746-1754. 10.1016/j.soard.2019.08.025

11. Docimo Jr. S, Rahmana U, Bates A, Talamini M, Pryor A, Spaniolas K: Concomitant hiatal hernia repair is more common in laparoscopic sleeve gastrectomy than during laparoscopic Roux-en-Y gastric bypass: an analysis of 130,772 cases. Obes Surg. 2019, 29:744-746. 10.1007/s11695-018-3594-0

12. Borbely Y, Kroll D, Nett PC, Moreno P, Tutuian R, Lenglinger J: Radiologic, endoscopic, and functional patterns in patients with symptomatic gastroesophageal reflux disease after Roux-en-Y gastric bypass. Surg Obes Relat Dis. 2018, 14:764-768. 10.1016/j.soard.2018.02.028

13. Aghajani E, Jacobsen HJ, Nergaard BJ, Hedenbro JL, Leifson BG, Gislason H: Internal hernia after gastric bypass: a new and simplified technique for laparoscopic primary closure of the mesenteric defects. J Gastrointest Surg. 2012, 16:641-645. 10.1007/s11605-011-1790-5

14. Santos E, Santa Cruz F, Hinrichsen EA, Ferraz AAB, Campos JM: Internal hernia following laparoscopic Roux-en-Y gastric by-pass: indicative factors for early repair. Arq Gastroenterol. 2019, 56:160-164. 10.1590/s0004-2803.201900000-32

15. Nguyen NT, Christie C, Masoomi H, Matin T, Laugenour K, Hohmann S: Utilization and outcomes of laparoscopic versus open paraesophageal hernia repair. Am Surg. 2011, 77:1353-1357. 10.1177/000313481107701018

16. DeMeester SR: Laparoscopic paraesophageal hernia repair: critical steps and adjunct techniques to minimize recurrence. Surg Laparosc Endosc Percutan Tech. 2013, 23:429-435. 10.1097/SLE.0b013e3182a12716 